\section{KENTRON}

REVUE PLURIDISCIPLINAIR

DU MONDE ANTIQUE

\section{Kentron}

Revue pluridisciplinaire du monde antique

22 | 2006

La démesure (suite 2)

\title{
Alexandre le Grand en Iran. Le Dârâb Nâmeh d'Abu Tâher Tarsusi, traduit et annoté par Marina Gaillard
}

Corinne Jouanno

\section{OpenEdition}

Journals

Édition électronique

URL : http://journals.openedition.org/kentron/1792

DOI : 10.4000/kentron. 1792

ISSN : 2264-1459

Éditeur

Presses universitaires de Caen

Édition imprimée

Date de publication : 31 décembre 2006

Pagination : 225-226

ISBN : 2-84133-296-0

ISSN : 0765-0590

\section{Référence électronique}

Corinne Jouanno, «Alexandre le Grand en Iran. Le Dârâb Nâmeh d'Abu Tâher Tarsusi, traduit et annoté par Marina Gaillard », Kentron [En ligne], 22 | 2006, mis en ligne le 21 mars 2018, consulté le 18 novembre 2020. URL : http://journals.openedition.org/kentron/1792 ; DOI : https://doi.org/10.4000/kentron.1792

\section{(C) $\Theta \Theta \Theta$}

Kentron is licensed under a Creative Commons Attribution-NonCommercial-NoDerivatives 3.0 International License. 
ostension de figures des organes de la génération qui seront ensuite enfouies dans le sol, autant de rites qu'on retrouve à Éleusis. Winkler rappelle aussi qu'on connaît beaucoup de fêtes féminines (privées) en l'honneur d'autres divinités, de caractère agraire, sans précisions sur leur contenu.

Une des deux Annexes qui terminent l'ouvrage porte sur un point de vocabulaire particulier («Phusis et Natura dans le sens d’organes génitaux»). Suivent une très copieuse bibliographie (p. 409-430) et une série d'Indices (p. 431-444) qui facilitent une bonne exploitation des ressources multiples de l'ouvrage. Celui-ci se présente comme un texte fondamental dans la genèse des études sur la sexualité antique, même si beaucoup de ces idées, audacieuses à l'époque, sont passées maintenant dans le domaine public. C'est un effet de la multiplicité des ouvrages qui ont paru au cours de ces dernières décennies, pour combler des lacunes qui ne sont désormais plus admises dans notre connaissance du monde grec antique.

François JouAN

\section{Alexandre le Grand en Iran. Le Dârâb Nâmeh d'Abu Tâher Tarsusi, traduit et annoté par Marina Gaillard, Paris, de Boccard, 2005, 435 pages.}

C'est un Alexandre inattendu que nous permet de découvrir le livre de Marina Gaillard, large sélection d'extraits tirés du roman fleuve du conteur persan Tarsusi (XI'-XII ${ }^{e}$ siècles) : cet ouvrage offre en effet de l'illustre Conquérant une image ambivalente, que Marina Gaillard impute à l'hétérogénéité des traditions recueillies par Tarsusi et à la persistance, en pleine époque islamique, d'un courant hostile à Alexandre, hérité de l'Iran ancien qui voyait dans le conquérant macédonien le destructeur de l'empire perse et le persécuteur du zoroastrisme. Si le héros de Tarsusi possède divers points communs avec le protagoniste du Roman d'Alexandre grec, dont il est partiellement dérivé (il est pourvu d'une ascendance perse qui correspond à l'ascendance égyptienne du héros primitif, création d'un auteur alexandrin, et il lutte pour la propagation de l'islam, comme le protagoniste des adaptations byzantines du Roman lutte pour la foi chrétienne), les insuffisances dont le conteur persan a affublé son personnage le rendent bien différent de l'Alexandre idéalisé de la tradition grecque : il bénéficie certes, comme le héros du Pseudo-Callisthène, de la faveur divine - faveur que manifestent sa rayonnante beauté et le signe (un grain de beauté noir) qu'il porte au visage -, mais il est aussi l'homme des promesses non tenues, l'enfant prodige que la malédiction d'Aristote fait basculer dans la médiocrité, puisque, à la suite d'une dispute avec son précepteur, il perd tout son savoir et devient «pareil à un ignorant» (p. 132). C'est d'ailleurs une caractéristique notable du roman de Tarsusi que de multiplier les épisodes de confrontation entre roi et sage - confrontation dont Alexandre sort invariablement vaincu, «car le rang le 
plus élevé convient aux sages» (p.142): entouré d'une cohorte d'intellectuels au nombre desquels figurent évidemment Aristote, mais aussi, en vertu d'un anachronisme habituel en ce genre de textes, Hippocrate et Platon, promu mentor du jeune roi, le héros de Tarsusi a constamment besoin du secours des sages pour échapper aux difficultés que lui créent ses voyages aux confins du monde. Plus surprenant encore pour le lecteur familier du Roman d'Alexandre grec, dont le protagoniste doit à ses seules vertus guerrières et stratégiques ses innombrables victoires, le héros de Tarsusi a souvent recours à sa femme pour se tirer d'affaire! Avatar de Roxane, BurânDokht, fille de Dârâb (alias Darius), est en effet l'une des multiples figures d'amazones qui peuplent le Dârâb Nâmeh, et cette belle, mais très virile héroïne, que sa lèvre ombragée d'un soupçon de moustache fait ressembler à un jeune homme, ne se contente pas, une fois devenue l'épouse d'Alexandre, de partager avec lui les hasards du combat: à maintes reprises, elle prend les armes pour venir à sa rescousse, lorsqu'il est en fâcheuse posture, et si, en mourant de chagrin moins d'un an après son époux, elle connaît une fin conforme aux exigences du code romanesque, l'évocation répétée des prouesses accomplies par elle au profit du Conquérant n'en contribue pas moins à ternir considérablement la gloire du héros persan, au point que l'Alexandre de Tarsusi apparaît parfois comme un «anti-héros risible» (p. 58).

Corinne Jouanno 